\title{
Dynamic analysis of communication transmission tower based on finite element method
}

\author{
Xingwu Kang a , Yongwei Zhang ${ }^{\text {b }}$ \\ Xi'an High-Tech Institute, Xi'an, 710025, China \\ akangxwu@sohu.com, binsistering@163.com
}

\begin{abstract}
Communication transmitting tower is an important part of communication engineering, analyzing structural characteristics and dynamic characteristics of the tower has practical significance. The three-dimensional model of communication tower is established by Solidworks, and the model is simulated and analyzed by finite element analysis software Workbench ANSYS in this paper. Then the 10 order non-zero modal frequency are obtained. Finally, simulation analysis of displacement response spectrum of simulated earthquake action is carried out, the equivalent stress and the direction of displacement are obtained. The result shows that the dynamic characteristics of the tower are complex and the modal shapes are varied. The communication tower achieves the design requirements of earthquake intensity. These conclusions provide a reliable theoretical basis for the structure optimization of the tower.
\end{abstract}

Keywords: Communication transmitting tower; ANSYS Workbench; Finite element analysis; Modal.

\section{Introduction}

China is an earthquake-prone country. The previous earthquake experience proved that although the communication tower has excellent seismic performance, some high towers and communication facilities at the top are prone to serious destruction. The flexural rigidity of communication tower is comparatively low since it is of steel-frame structure with great height and lateral dimension ratio. As being affected by transverse load, wind load and earthquake load are prone to causing larger vibration and deformation of tower. In addition, seismic load is significantly destructive to the structure [3-7]. Finite element analysis is an international mainstream analytical method. Large-scale finite element analysis software possesses mature and reliable processing function [8]. Traditional finite element communication tower analysis establishes modeling with beam bar elements, and seldom analyzes combining with modal analysis and earthquake response spectrum [9-11]. The paper established a communication tower entity unit model combined with large-scale finite element analysis software ANSYS Workbench to perform analysis and research closer to the actual situation on the structural modal frequency, vibration mode and earthquake response spectrum which has provided theoretical basis for the optimization of tower construction in the future, and has provide certain reference value for the a seismic design of communication tower.

\section{To establish a finite element model of communication tower}

Communication tower is composed of tower frame, guide line and communication facilities. Tower frame is the major stress component of communication tower. Tower bars are subject to rigid coupling. Angle members are connected with eccentric bolts. The analysis focuses on tower frame in this paper. Furthermore, the principal material of communication tower not only has to bear the axial force, but also shear force and bending moment. The main diagonal material and auxiliary materials of the communication tower adopts bond contact to simulate bolt contact with less impact on the experimental results of the structure. The communication tower is $22 \mathrm{~m}$ in height, $3 \mathrm{~m}$ in width at the bottom, and $0.5 \mathrm{~m}$ in width at the top. The main diagonal material and auxiliary materials of the tower are made of Q345 steel with a elasticity modulus of 2.06GPa, a Poisson's ratio of 0.28 and density of $7850 \mathrm{~kg} / \mathrm{m}^{\wedge} 3$. In addition, take $50 \mathrm{KG}$ of quality points at the tower top to simulate related communication equipment. The communication tower height is the positive axis of $\mathrm{Y}$ which is 
perpendicular to $\mathrm{XOZ}$ plane. Axis $\mathrm{X}$ and $\mathrm{Y}$ are the symmetry axis of communication tower cross section. The two intersect at the geometric center. The three form Descartes right rectangular coordinate system. In order to get reliable results and consider the solving speed and calculation accuracy, the paper selects tetrahedral mesh unit model for mesh generation, and advanced functions for solution since there are many communication tower mold units and vibration modes of the communication tower mold. Communication tower CAD mold 1 of ANSYS Workbench are as shown in Fig. 1. Totals of 653,847 nodes and 344,859 units are generated.
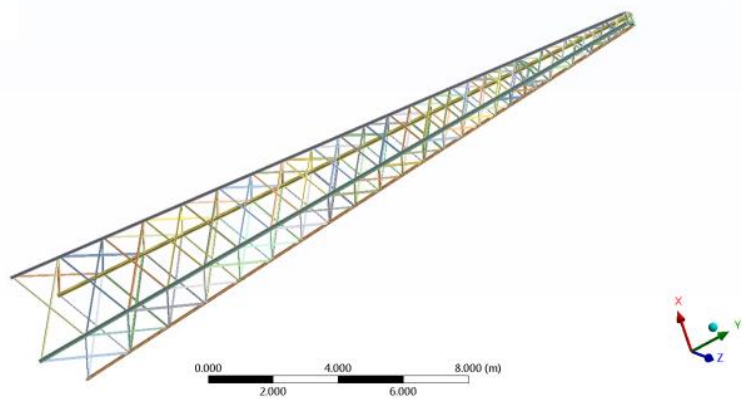

Fig. 1 CAD mold of communication tower

\section{Communication towers modal analysis}

To avoid resonance of communication tower under various working conditions, generally it is required to calculate the modal frequency and vibration mode of communication tower. Free modal analysis method is adopted in the paper without any constraint nor load. Extracting the first 10 order non-zero modal frequency as shown in Fig. 2.

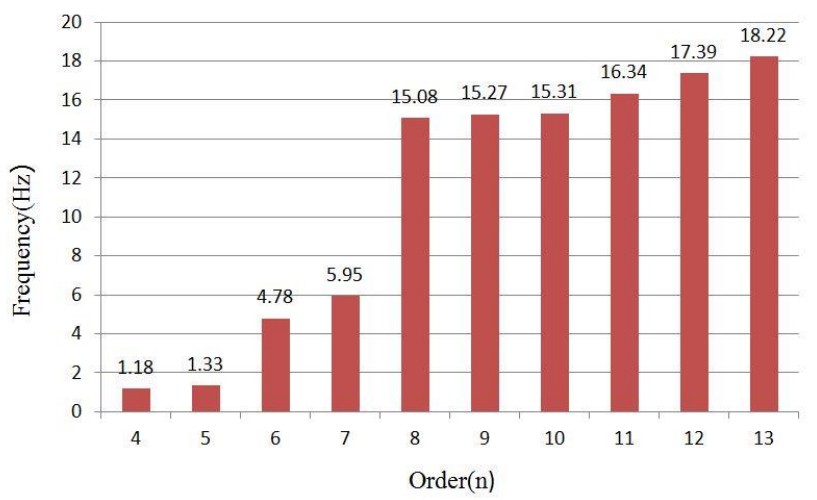

Fig. 2 The first 10 order non-zero modal frequency

Due to the existing modal vibration mode, the 4th, 6th, 7th, 9th and 11th modal is specifically analyzed as shown in Fig. 3 to Fig. 7.
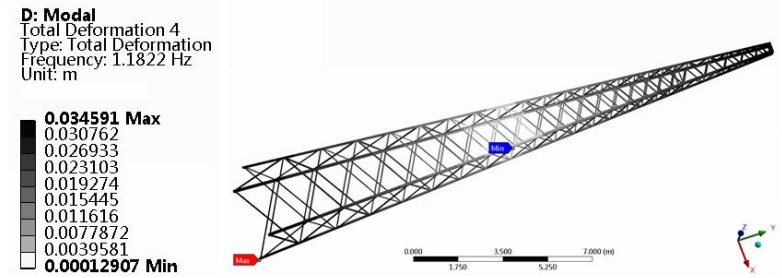

Fig. 3 The 4 th order of model vibration
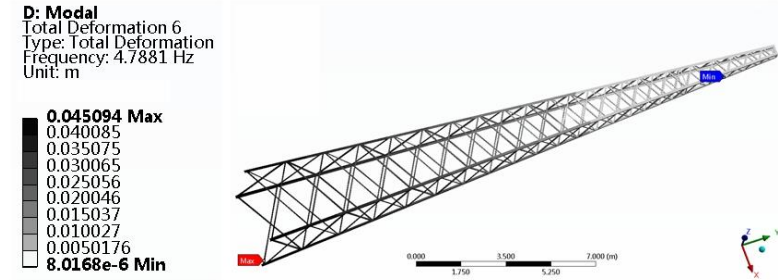

Fig. 4 The 6th order of model vibration 

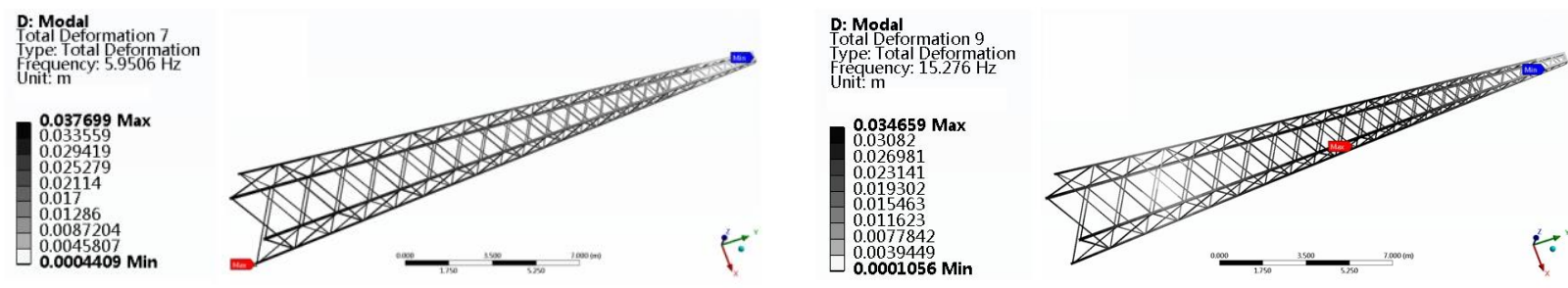

Fig. 5 The 7 th order of model

vibration

Fig. 6 The 9th order of model
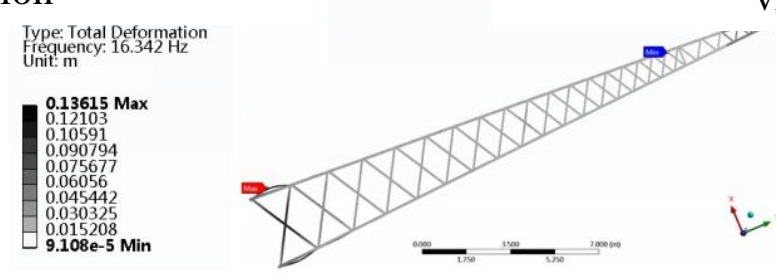

vibration

Fig. 7 The 11th order of model vibration

The characteristics of vibration mode changes of the communication tower as shown in table 1.

Table 1 Characteristics of vibration mode of communication tower

\begin{tabular}{cccccc}
\hline Number of order & 4 & 6 & 7 & 9 & 11 \\
\hline Frequency(Hz) & 1.18 & 4.78 & 5.95 & 15.27 & 16.34 \\
\hline $\begin{array}{c}\text { Characteristics of } \\
\text { vibration mode }\end{array}$ & $\begin{array}{c}\text { Vibration at } \\
\text { direction Z }\end{array}$ & $\begin{array}{c}\text { Vibration at } \\
\text { the maximum } \\
\text { deformation at } \\
\text { bottom }\end{array}$ & $\begin{array}{c}\text { Rotate around } \\
\text { axis Y }\end{array}$ & $\begin{array}{c}\text { Vibration at } \\
\text { direction Y with } \\
\text { the maximum } \\
\text { deformation at } \\
\text { the middle } \\
\text { section }\end{array}$ & $\begin{array}{c}\text { Slightly bend } \\
\text { torsion coupling } \\
\text { and oblique } \\
\text { material } \\
\text { vibration }\end{array}$ \\
\hline
\end{tabular}

\section{Earthquake response spectrum analysis of communication tower}

It is necessary to learn the displacement of vibration system and maximum accelerated speed at engineering practice, namely the maximum response value of the material under impulse load. The relation curve of the maximum response value and incentive duration is known as response spectrum. Response spectrum module of ANSYS Workbench can be adopted to perform anti-earthquake analysis for communication tower structure via response spectrum method. Response spectrum is an analysis technology to calculate the model stress. It can link the modal analysis results and known spectrum.

Modal response spectrum analysis is mainly divided to single point response spectrum analysis and multiple point response spectrum analysis. Specify a response spectrum response on a point set of model as single point response spectrum analysis; specify different response spectrum responses on different point sets as multiple point response spectrum analysis. The paper adopts single point response spectrum response analysis. The action direction of seismic displacement spectrum is vertical, applying on the four fixed supporting points of communication tower respectively. At present, EI-Centro wave, Taft wave and Qian an wave are the most frequently-used seismic waves for structure analysis. The seismic displacement frequency spectrum in the paper is selected from EI-Centro wave. The spectrum data is as shown in Table 2. 
Table 2 EI-Centro Wave displacement spectrum

\begin{tabular}{ccccc}
\hline Frequency $(\mathrm{Hz})$ & 0.5 & 1 & 2.4 & 3.8 \\
Displacement $(\mathrm{cm})$ & 25 & 12 & 20 & 16 \\
Frequency $(\mathrm{Hz})$ & 17 & 18 & 20 & 32 \\
Displacement $(\mathrm{cm})$ & 25 & 18 & 20 & 7.5 \\
\hline
\end{tabular}

The equivalent stress and displacement diagram at the direction of $\mathrm{X}, \mathrm{Y}$ and $\mathrm{Z}$ calculated through the above simulation calculation are as shown in Fig. 8 to Fig. 11.

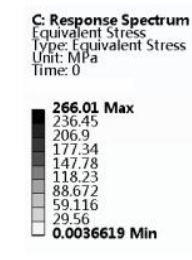

Fig. 8 Seismic response equivalent stress of communication tower
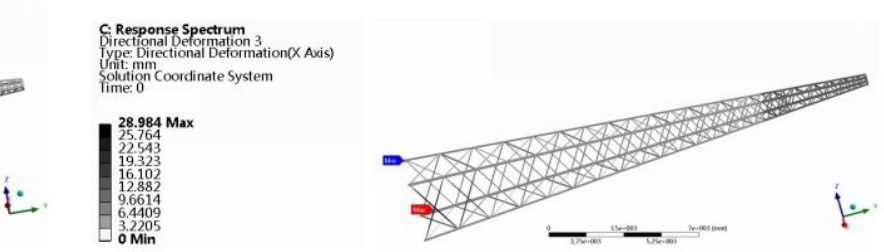

Fig. 9 Displacement diagram of communication tower at direction $\mathrm{X}$
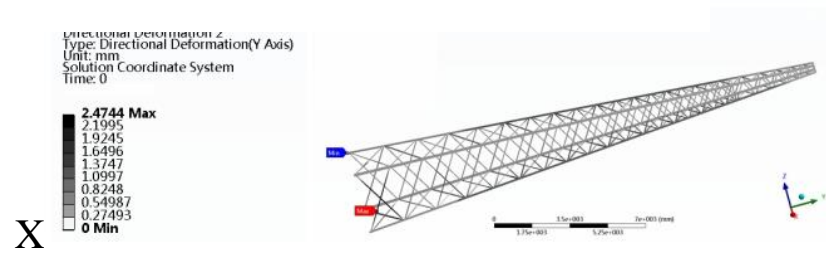

Fig. 10 Displacement diagram of communication tower at direction $\mathrm{Y}$
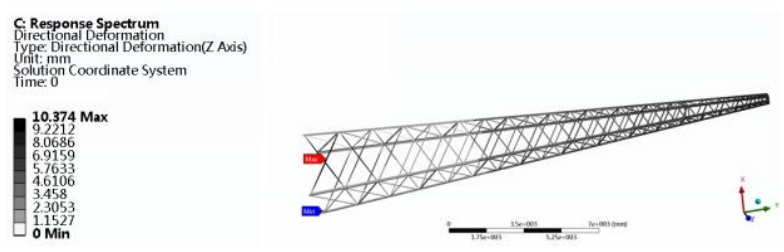

Fig. 11 Displacement diagram of communication tower at direction $\mathrm{Z}$

The maximum stress value of communication tower is $266 \mathrm{MPa}$ which is occurred at the bottom of communication tower. The yield limit of material Q345 is $345 \mathrm{MPa}$. It can be seen from simulation results that the communication tower intensity can satisfy seismic intensity requirement. It can be seen from the displacement deformation diagram on the three directions that the maximum communication tower deformation is $28.98 \mathrm{~mm}$ which is smaller than the maximum value, $70 \mathrm{~mm}$ as required in Code for seismic design of building, and that the communication tower can satisfy the deformation requirements of seismic test.

Based on the analysis and simulation results above, it's obvious that the communication tower can satisfy the deformation requirements of seismic test.

\section{Summary}

The paper performed modal analysis for communication tower combining with large-scale finite element analysis software ANSYS Workbench. It turned out that the communication tower in the paper is characterized of excellent structural performance, uniform structural internal force distribution, high rigidity and small displacement. The stress satisfies the requirements. The low-order mode of communication tower is mainly for bending vibration. The higher-order mode refers to torsional vibration and bend torsion coupling vibration. The diversity of vibration mode indicates that the dynamic characteristics of communication tower are complicated. According to the analysis of seismic response spectrum, the bottom of the communication tower is subject high stress. 
And the deformation of diagonal materials and auxiliary materials is obvious. However, the overall rigidity of tower is high and complies with anti-seismic requirements.

\section{References}

[1] Zang Zhansheng, Huang Weixue and Sun Guoliang. Discussion of communication base station earthquake damage hierarchies [J]. Earthquake Engineering and Engineering Vibration. Vol. 34 (2014) No. 10, p.1025-1030.

[2] Wang Xinpei, Liuhong, Liu Chunguo et. al. Communication building earthquake damage assessment based on seismic damage matrix [J] Telecom Engineering Technics and Standardization. (2012) No.12, p. 68-72.

[3] Cuiqiang. Steel structure tower dynamics analysis based on ANSYS [J]. Coal Mine Machinery. Vol. 34(2013) No. 4, p. 132-133.

[4] Wenfang, Jiangyi etc. Finite element analysis of integrated communication tower [J]. Equipment Manufacturing Technology. Vol. 7(2015) No. 7, p. 12-13.

[5] Xiaoqi, Zhou Lingfeng, Cai Jingtai Etc. Compact narrow ANSYS modeling and dynamic analysis of transmission tower [J]. Water Resources and Power. Vol. 29 (2011) No. 2, p. $167-168$

[6] Li Meiguo, Yandong and Wangjin. Finite element analysis of hard and soft combination tower structure [J] Coal electrical machinery. (2011) No. 4, p. 86-87.

[7] Zhangfeng, Yang Lipeng. Impact of finite element model on mechanical analysis for transmission towers [J]. Guangdong Power Grid. Vol. 23 (2010) No. 12, p. 47-49.

[8] Pu Guangyi .Description of ANSYS Workbench basic instruction and example explanation [M]. Beijing: China Water Power Press. 2013.

[9] Mu Yuliang, Liu Qiaoying and Zhangbo. Basic natural vibration period analysis and seismic applications of single pipe communication tower structure [J]. North China Earthquake Sciences. Vol. 29(2011) No. 4, p. 58-60.

[10]Zhao Yuming, Wangli and Lu Yulin. Seismic dynamic response analysis of high communication tower [J], Modern Electronics Technique. Vol. 38(2015) No. 16, p. 16-19.

[11] Yan Anzhi, Zhi Xiaoxiao, Duan Qiaoqiao and Wang Qinting. Modal analysis and response under the seismic load of drum type transmission tower [J], Luoyang Institute of Technology. Vol. 23(2013) No. 2, p. 16-22. 